\section{CIRCUITO DE ATIVIDADES COMO FERRAMENTA AUXILIAR NA FORMAÇÃO DO EDUCADOR AMBIENTAL}

\author{
Circuit of activities as an auxiliary tool in the development of the environmental educator
}

Circuito de actividades cómo herramienta auxiliar en la formación del educador ambiental

\section{Resumo}

Em uma sociedade contemporânea a Educação Ambiental deve ser o início para o desenvolvimento do planejamento o ambiental, social, político, econômico e cultural. Este trabalho apresenta uma alternativa para estimular o desenvolvimento da Educação Ambiental nas escolas por meio de atividades lúdicas em circuito. $\mathrm{O}$ estudo foi aplicado aos acadêmicos do curso de Licenciatura em Ciências Biológicas no Instituto Federal do Paraná Campus Umuarama. O objetivo foi verificar a relevância das atividades lúdicas em circuito no processo de formação de educadores ambientais. Nesse sentido, espera-se que possam aplicar o sistema sugerido em suas práxis docentes. Durante o estudo, os acadêmicos organizados em grupos participaram da execução de sete atividades em ordem delineada. Para avaliar a eficácia do sistema, foi aplicado um questionário visando mensurar a apropriação e o envolvimento dos participantes. Concluiu-se que as atividades lúdicas em circuito representam uma importante ferramenta para a Educação Ambiental.

Palavras-Chave: Dinâmicas de grupo; Técnicas de ensino-aprendizagem; Oficina de Educação Ambiental.

\section{Abstract}

In a contemporary society Environmental Education should be the beginning for the development of environmental, social, political, economic and cultural planning. This project presents an alternative to stimulate the development of Environmental Education in schools through ludic activities in circuit. The study was applied to the undergraduate students of Biological Sciences at the Instituto Federal do Paraná Campus Umuarama (Federal Institute of Paraná - Umuarama Campus). The aim was to verify the relevance of the ludic activities in circuit in the process of training environmental educators. In this sense, it is hoped that they will be able to apply the suggested system in their teaching praxis. During the study, the academics organized in groups participated in the execution of seven activities in outlined order. To evaluate the effectiveness of the system, a questionnaire was applied to measure the appropriation and the involvement of the participant. It was concluded that the ludic activities in circuit represent an important tool for Environmental Education.

Keywords: Group dynamics; Teaching-learning activities; Environmental Education workshop.

\section{Resumen}

En una sociedad contemporánea la Educación Ambiental debe ser el início para el desarrollo del planeamiento ambiental, social, político, económico y cultural. Este trabajo presenta una alternativa para impulsar el desarrollo de la educación ambiental en las escuelas por el medio de actividades lúdicas en circuito. Ese estudio fue aplicado a los estudiantes de la carrera de Ciencias Biológicas en el Instituto Federal do Paraná campus Umuarama. El objetivo fue verificar la relevancia de las actividades lúdicas en circuito en el proceso de formación de los educadores ambientales. En ese sentido, se espera que sea posible aplicar el sistema sugerido en su practica docente. Durante el estudio, los académicos organizados em grupos participaran en la ejecución de siete actividades en orden determinada. Para evaluar la eficacia del sistema, fue aplicado un cuestionario para valorar la apropiación e involucración de los participantes. La conclusión fue que las actividades lúdicas en circuito simbolizan una importante herramienta pata la educación ambiental.

Palabras clave: Dinámica en grupo; Técnicas de enseño aprendizaje; Taller de Educación ambiental.

\section{AUTORAS:}

NORMA BARBADO'

ORCID 0000-0002-0562-3958

${ }^{1}$ Instituto Federal do

Paraná (IFPR)

JULIANA CONTER PEREIRA

KOBREN ${ }^{2}$

ORCID 0000-0002-7249-6952

${ }^{2}$ Universidade Estadual de Maringá (UEM)

LUCIANA NUNES DOS

SANTOS 3

ORCID 0000-0003-2147-5315

3 Universidade Estadual de Maringá (UEM)

PAULA ANDRÉIA GOMES DA

CRUZ4

ORCID 0000-0001-7701-4724

${ }^{4}$ Universidade Estadual de Maringá (UEM)

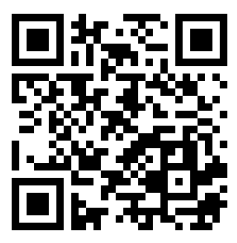

Para citar este artigo:

BARBADO, N.; KOBREN, J. C. P.; SANTOS, L. N.; CRUZ, P. A. G. Circuito de atividades

como ferramenta auxiliar na formação do educador ambiental.

Revista Eletrônica Ludus Scientiae, Foz do Iguaçu, v. 03, n. 01, p. 87-99, jan./jul. 2019. 


\section{INTRODUÇÃO}

A questão ambiental, desventura que acomete a humanidade como um todo, requer ação educativa. Por meio de processos de Educação Ambiental (EA) almeja-se, em todos os níveis de ensino, a conscientização acerca da crise ambiental e a consecução de transformações nos indivíduos, com mudanças de valores e comportamentos.

No Brasil, a EA foi incluída na Constituição Federal de 1988. Não obstante, a Lei no 9.795/99 dispõe sobre a EA e institui a Política Nacional de Educação Ambiental. Segundo ela, a EA consiste em processos pelos quais o indivíduo e a coletividade constroem valores sociais, conhecimentos, habilidades, atitudes e competências voltadas para a conservação do meio ambiente (BRASIL, 1999).

A preocupação com a valorização da EA tem culminado na formação de educadores ambientais interdisciplinares, que visam à provocação de mudanças e alteração de comportamentos no intuito de minimizar a degradação do meio ambiente (CARVALHO, 2017). Porém, no ensino formal, não há um componente curricular específico para tratar do assunto.

Para Layrargues e Lima (2014), essa prática educativa tornou-se mais complexa do que se possa imaginar. Os autores afirmam que a EA, no final do Século XX, girava em torno de relações estabelecidas entre indivíduo, sociedade, educação e natureza, num universo pedagógico multidimensional, desdobrando-se em diversas análises e aportes teóricos de crescente sofisticação.

Apesar da proximidade com as ciências biológicas, atualmente a EA está definida como educação política, com análise de relações econômicas, políticas, sociais e culturais entre a humanidade e o meio ambiente, relacionando o "por que" com o "como" fazer (REIGOTA, 2017). Dessa forma, as atividades de EA não são de responsabilidade exclusiva do professor de Ciências e/ou Biologia, mas sim de toda a comunidade escolar que deveria se envolver com a importante missão de formar cidadãos conscientes ambientalmente.

Nesse contexto, considerando a EA como forma abrangente de educação crítica, é possível enfatizar a ludicidade como forma do processo educativo ambiental para mudança de valores e atitudes, em contraposição à forma conservacionista. A EA conservadora não questiona a estrutura social vigente em sua totalidade, apenas pleiteia reformas setoriais, com mudanças que dificilmente se concretizariam por questões econômicas e políticas (LAYRARGUES e LIMA, 2014). Essa vertente se vincula à "pauta verde" e se relaciona com crianças em idade escolar objetivando trabalhar apenas o amor pela natureza (LAYRARGUES, 2012).

Com vistas a contemplar a macrotendência crítica da EA, com um forte viés sociológico e político, os educadores ambientais devem proporcionar debates a partir de conceitos-chave, como: democracia, emancipação, cidadania, justiça ambiental, conflito, participação e transformação social (LAYRARGUES e LIMA, 2014).

Por envolverem uma diversidade de recursos didáticos, as atividades lúdicas servem de ligação para facilitar a relação entre professor, aluno e o conhecimento, em um momento basilar da elaboração do saber (KAWAMOTO e CAMPOS, 2014). Outrossim, podem ser aplicadas em todos os níveis de ensino: fundamental, médio ou superior.

Destarte, as atividades lúdicas voltadas à EA conduzem à conscientização sobre a forma de perceber o que é o meio ambiente e a necessidade de preservá-lo. Assim, atividades prazerosas e favoráveis ao aprendizado podem ser proporcionadas, principalmente pelo fato de permitirem que se traga ao ambiente escolar situações reais que, muitas vezes, não poderiam ser vivenciadas (EVANGELISTA e SOARES, 2011). 
As atividades lúdicas propostas no processo educacional contemplam os critérios para uma aprendizagem efetiva entre os envolvidos. Além de chamar a atenção para o assunto, enseja a discussão entre os participantes transportando, por conseguinte, o conhecimento para a realidade. Dessa forma, a motivação adquire o sentido de elemento necessário à apreensão dos conceitos na rede de significados de cada indivíduo (SILVA, METTRAU e BARRETO, 2007).

Diante do exposto, este estudo teve como objetivo verificar a relevância das atividades lúdicas em circuito no processo de formação de educadores ambientais.

\section{MATERIAL E MÉTODOS}

O circuito, composto por o7 (sete) atividades, foi realizado no primeiro semestre de 2018, quando da realização da campanha Ciclo Siete (Olimpíadas para a sustentabilidade nos países iberoamericanos) organizada pelo Instituto Federal do Paraná - Campus Umuarama. Por iniciativa colombiana, o Ciclo Siete consiste na realização de ações com temáticas sustentáveis a fim de conscientizar pessoas nos países ibero-americanos. Tais ações são desenvolvidas e aplicadas em escolas, universidades e demais instituições preocupadas com a sustentabilidade.

Inserido neste contexto, foram aplicadas atividades lúdicas aos alunos da Licenciatura em Ciências Biológicas $\left(1^{\circ}\right.$ ao $4^{\circ}$ ano), com o fito de propor a prática de aprendizagem da EA e sugerir o sistema aos futuros docentes que poderão atuar como educadores ambientais. Para organização do circuito, utilizou-se o ginásio de esportes e um laboratório de informática da instituição. $\mathrm{O}$ material utilizado nas ações foi produzido por meio da reutilização de materiais aplicados em oficinas de EA em outras ocasiões.

No circuito organizado, participaram cerca de 100 (cem) acadêmicos de biologia, os quais foram distribuídos em grupos, de modo a viabilizar a passagem de todos pela mesma sequência no ciclo de atividades. No início de cada ação, houve explicação sobre o seu funcionamento. Ao final, apresentaram-se ao grupo os objetivos da prática exercida para a reflexão e discussão. $\mathrm{O}$ nome das atividades, o número de participantes e o material utilizado no circuito estão citados no Quadro 1.

Quadro 1: Material utilizado no circuito e número de participantes de cada atividade. Fonte: Elaborado pelas autoras.

\begin{tabular}{|c|c|c|c|c|c|c|c|}
\hline 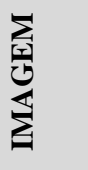 & 1 & (coi) & $\pi E$ & & & & ?II \\
\hline 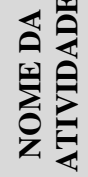 & $\begin{array}{c}\text { Atividade } 1 \\
\text { Abrigo, água e } \\
\text { alimento }\end{array}$ & $\begin{array}{c}\text { Atividade } 2 \\
\text { Imagem e } \\
\text { ação }\end{array}$ & $\begin{array}{l}\text { Atividade } 3 \\
\text { Formação de } \\
\text { nomes de } \\
\text { animais }\end{array}$ & $\begin{array}{l}\text { Atividade } 4 \\
\text { Conhecendo as } \\
\text { espécies: macho } \\
\text { e fêmea }\end{array}$ & $\begin{array}{c}\text { Atividade } 5 \\
\text { Jogo de } \\
\text { palavras }\end{array}$ & $\begin{array}{c}\text { Atividade } 6 \\
\text { Monstro do } \\
\text { lixo }\end{array}$ & $\begin{array}{c}\text { Atividade } 7 \\
\text { Pegada } \\
\text { ecológica }\end{array}$ \\
\hline 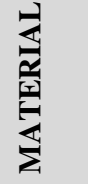 & --- & $\begin{array}{l}\text { Crachás com } \\
\text { a impressão } \\
\text { de animais }\end{array}$ & $\begin{array}{l}\text { Cartas com } \\
\text { letras }\end{array}$ & $\begin{array}{l}\text { Fichas com } \\
\text { nomes de } \\
\text { animais }\end{array}$ & $\begin{array}{c}\text { Cartas com } \\
\text { palavras }\end{array}$ & Lixo & $\begin{array}{l}\text { Computadores } \\
\text { com acesso à } \\
\text { internet }\end{array}$ \\
\hline
\end{tabular}




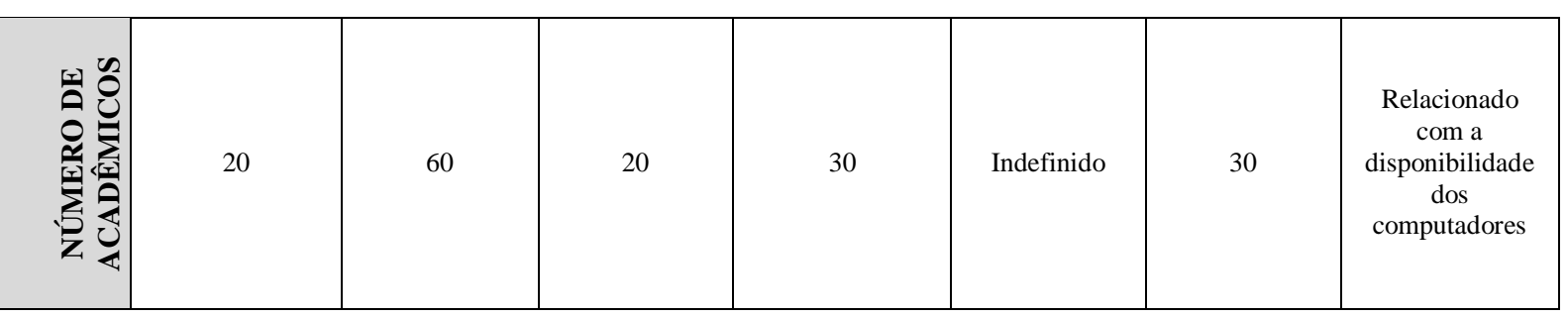

As atividades, descritas a seguir, foram organizadas de forma sistêmica para reunir diversas reflexões sobre problemática ambiental contemporânea como meio de transformação comportamental.

Atividade 1: Abrigo, água e alimento. Local de aplicação: Ginásio de Esportes. O monitor da atividade apresentou três símbolos formados por gestos das mãos para representação do abrigo, água e alimento. A equipe com número par de participantes dividiu-se em dois grupos, posicionando-se em duas filas. Os acadêmicos, que se dispuseram em filas contrárias, decidiram um dos três símbolos formados pelas mãos. Depois do sinal realizado pelo monitor, os alunos se viraram para procurar um par com o mesmo gesto por si posicionado. Os acadêmicos sem par saíram da atividade. A prática prosseguiu até que restasse um par de alunos. Esta atividade permite ao participante perceber as necessidades básicas dos seres vivos (abrigo, água e alimento) bem como a problemática causada pelo desequilíbrio ecológico.

Atividade 2: Imagem e ação. Local de aplicação: Ginásio de Esportes. Um aluno se posicionou em frente ao público e recebeu um crachá nas costas com a imagem de um animal, somente a plateia o visualizou. No decorrer da atividade, a plateia representou o animal por meio de mímicas para que fosse desvendado pelo acadêmico com o crachá. A atividade foi realizada sem a pronúncia de palavras. Para provocar o desenvolvimento das habilidades psicomotoras, a atividade foi realizada com tempo limitado de 03 (três) minutos. Esta ação auxilia no desenvolvimento da criatividade, concentração, agilidade motora, capacidade simbólica e na prática do trabalho em grupo. Além disso, permite a demonstração da percepção de gestos e atitudes de importantes animais ameaçados de extinção.

Atividade 3: Formação de nomes de animais. Local de aplicação: Ginásio de Esportes. Foram organizados 02 (dois) grupos, a partir do tempo estabelecido de 05 (cinco) minutos. Uma equipe recebeu as cartas com as letras para formação de palavras que correspondem a nomes de animais. O grupo que formou o maior número de palavras venceu a competição. No decorrer da atividade os grupos não visualizaram as palavras que foram formadas para que nenhuma equipe ficasse em vantagem. Esta ação propicia o pensamento rápido e sistêmico, concentração, integração de grupo e a prática competitiva. Além disso, relembra nomes de importantes representantes da fauna.

Atividade 4: Conhecendo as espécies: macho e fêmea. Local de aplicação: Ginásio de Esportes. O grupo, formado por 30 (trinta) acadêmicos, se organizou em círculo. Cada integrante recebeu uma ficha contendo um substantivo (nome de um animal do gênero masculino ou feminino). Os estudantes foram orientados a lê-la, posicioná-la à frente de seu corpo para que os demais envolvidos também a vissem. Feito isso, iniciou-se a busca pelo par referente ao animal que carregava consigo. Ao achar o par correspondente à sua ficha, o participante se posicionava ao lado estabelecido pelos aplicadores, com seu par. Após a formação de pares, realizou-se a conferência da correlação e, em havendo equívoco, os pares equivocados faziam nova busca entre si até que todos os pares estivessem corretos. A ação foi realizada em várias rodadas, devido ao elevado número de grupos. Esta atividade estimula o interesse do aluno em relação ao gênero de distintas espécies de animais, evidenciando a dificuldade de espécies em extinção de encontrar seus pares para acasalamento na natureza. 
Atividade 5: Jogo de palavras. Local de aplicação: Ginásio de Esportes. Divididos em grupos (de acordo com a quantidade de frases distintas e disponíveis para a atividade), os estudantes receberam fichas separadas e embaralhadas em palavras correspondentes a uma frase. Anunciado o início da formação das frases, todos os alunos em suas respectivas equipes, espalharam as fichas no piso e foram incentivados a formarem a frase corretamente no menor tempo possível. Após conferência e confirmação, os acadêmicos foram instruídos à leitura em voz alta para os demais integrantes da atividade. A cada finalização e conferência das demais equipes, realizou-se a leitura em voz alta até o término da formação de todas as frases. Esta atividade incentiva o despertar da consciência do aluno para as atitudes de conservação ao meio ambiente, percebendo-se como ser integrante, dependente e transformador.

Atividade 6: Monstro do lixo. A atividade foi realizada em 02 (duas) etapas, quais sejam: caminhada para coleta de materiais recicláveis indevidamente descartados no meio e construção de um monstro com os resíduos coletados. A primeira ação contou com a participação de equipes de estudantes que percorreram uma região predeterminada do município, num local de elevado adensamento populacional, para coleta de materiais recicláveis dispostos de maneira inadequada. Após, na segunda etapa (realizada neste circuito no Ginásio de Esportes), as equipes construíram o "monstro do lixo". Esta atividade pode acontecer com diferentes números de participantes. Ela promove a interação do aluno com o local no qual transcorre o seu dia a dia, da qual decorre reflexão acerca da geração e descarte inadequados dos resíduos sólidos na cidade. O monstro construído serve para sensibilização de toda a comunidade acadêmica a respeito da disposição final dos resíduos sólidos.

Atividade 7: Pegada ecológica. Na sala de informática, os acadêmicos acessaram o site do indicador de sustentabilidade "Pegada Ecológica", o qual confere todas as orientações de acesso e utilização. De acordo com as informações inseridas, baseado nos hábitos e estilos de vida próprios de cada aluno, realizou-se a análise dos dados informando a quantidade de recursos naturais renováveis necessários para manter o estilo de vida de cada indivíduo. Esta ação consiste em uma importante ferramenta para o cálculo do consumo e de seus impactos sobre os recursos ambientais. Visa mobilizar e incentivar os alunos a repensarem seus hábitos e a adotar práticas mais sustentáveis.

Por fim, como método de avaliação, foi elaborado e aplicado questionário (online) composto por 7 (sete) questões objetivas a uma amostra composta por 37 (trinta e sete) participantes do circuito. Os resultados e a interpretação dos dados obtidos estão descritos no próximo tópico.

\section{RESULTADOS E DISCUSSÃO}

As atividades aplicadas nas quatro turmas da licenciatura tiveram boa aceitação, considerandose que os alunos participaram efetivamente por livre e espontânea vontade. Além do mais, os acadêmicos demonstraram interesse e envolvimento com o tema proposto. No decorrer das dinâmicas foi possível verificar a sensibilização dos estudantes em relação às questões ambientais, tanto pela ludicidade das atividades sugeridas, quanto pela forma dinâmica de aplicação, em circuito. A Figura 1 apresenta as respostas obtidas pelos participantes avaliados em relação à percepção quanto ao grau de relevância das atividades que compuseram o circuito.
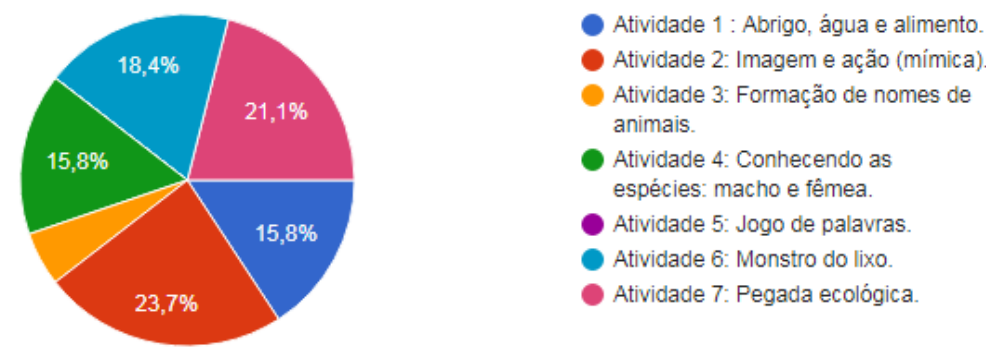
Figura 1: Relevância das atividades lúdicas utilizadas no circuito. Fonte: Elaborado pelas autoras.

A Atividade 2, imagem e ação, foi considerada a mais relevante pelos avaliados, obtendo $23,7 \%$ de representatividade. Durante a referida atividade houve reflexão sobre a importância da preservação ambiental para a fauna, bem como acerca da importância de cada espécie animal no ecossistema. Para Reverbel (1997), a prática de atividades globais de expressão (como a mímica) é fundamental na educação de crianças e adolescentes, uma vez que essas atividades buscam fornecer informações e, ao mesmo tempo, despertar um senso crítico nos estudantes. Faria, Dietrich e Gomes (2016) complementam que a mímica possibilita o desenvolvimento da criatividade, memória, bem como estimula sentimentos.

Campos et al. (2019) ressaltam que as instituições de ensino devem desenvolver, por fundamento, condutas e atitudes com responsabilidades e habilidades socioambientais nos indivíduos, para enfrentamento amplo e crítico das demandas ambientais. Sendo assim, infere-se que a inserção da Atividade 2 no contexto educacional objetiva despertar no indivíduo a valorização do equilíbrio ecológico, para que este desempenhe a competência crítica na sociedade.

Além da imagem e ação, dentre as atividades, as que tiveram maior destaque no circuito segundo os estudantes, foram as atividades 7 e 6 (pegada ecológica e monstro do lixo), com 21,1\% e $18,4 \%$, respectivamente. Essas atividades proporcionaram reflexões mais aprofundadas sobre a relação homem-natureza, o consumo de recursos naturais e as práticas inadequadas de descarte de resíduos sólidos, temas tão atuais, quanto importantes de serem trabalhados. Neste sentido, Campos et al. (2019) relatam que discentes de Barbacena - MG também responderam positivamente às dinâmicas de EA voltadas à tônica dos resíduos sólidos, o que refletiu nas taxas de segregação.

Destarte, observa-se que a EA como meio de obtenção do bem-estar de todos os seres vivos no ambiente natural, requer a inclusão e imersão dos indivíduos em experiências práticas acerca das querelas ambientais, a fim de influenciá-los e sensibilizá-los. Disterheft et al. (2015), afirmam que as abordagens participativas e as atividades extraclasse oportunizam mudanças de paradigmas, provocando reflexão sobre a relação entre o homem e os recursos naturais, corroborando para a inserção do conceito de sustentabilidade na cultura universitária.

Outrossim, fez-se necessário avaliar o grau de mobilização e sensibilização dos estudantes por meio das atividades desenvolvidas, conforme dados dispostos na Figura 2.

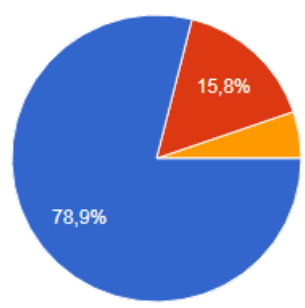

$$
\begin{aligned}
& \text { Sim. } \\
& \text { Talvez. } \\
& \text { Não. }
\end{aligned}
$$

Figura 2: Mobilização e sensibilização dos estudantes por meio das atividades desenvolvidas. Fonte: Elaborado pelas autoras.

A maioria $(78,9 \%)$ dos investigados afirmou que houve mobilização por meio das atividades desenvolvidas e que ficaram sensibilizados quanto às questões. Nesse sentido, Sacchetto et al. (2011) entendem que o ambiente lúdico consiste em um campo fértil para que a aprendizagem ocorra de maneira significativa. Sobre as contribuições dos jogos e brincadeiras no processo de ensino e aprendizagem da educação, Silva et al. (2019) concluíram que tais atividades desenvolvem a aprendizagem consciente no âmbito pedagógico na percepção de mundo, indo além da diversão. 
Ademais, estudos apontam que o ensino dinâmico contribui de forma significativa na aprendizagem em diversas áreas, da infância à terceira idade (CONDESSA, PEREIRA e PEREIRA, 2019; BIANCHESSI e MENDES, 2019; OLIVEIRA et al., 2012).

Desse modo, as questões seguintes buscaram avaliar a concepção dos estudantes no que concerne à forma lúdica de aprendizagem na EA das ações propostas, considerando que são acadêmicos da Licenciatura em Ciências Biológicas.
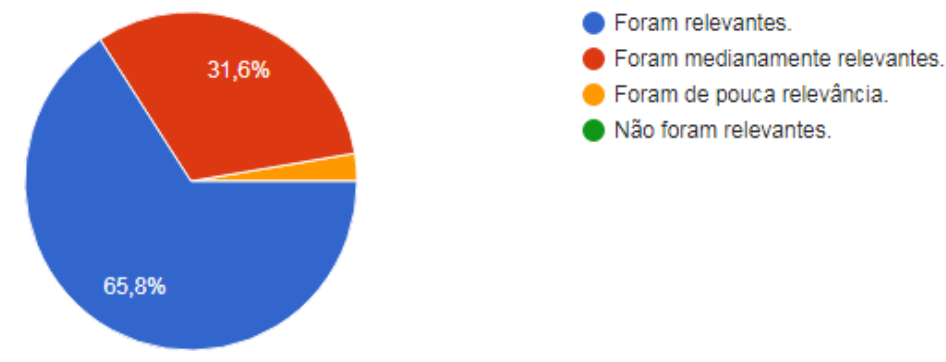

Não foram relevantes.

Figura 3: Ponderação das dinâmicas ministradas nas oficinas para aprendizagem dos conteúdos de Educação Ambiental como complemento da graduação. Fonte: Elaborado pelas autoras.

Conforme a Figura 3, no que tange à aprendizagem dos conteúdos ambientais aplicados, em que pese a avaliação positiva tenha ficado aquém da mobilização, ainda deve ser tida por relevante, pois alcançou o patamar de 65,8\%. Neste sentido, Oliveira et al. (2013) destacam que os estudos sobre o ponto de vista da EA na formação docente são primordiais para a construção de suas futuras práticas escolares.

As instituições de ensino possuem impactos significativos no meio ambiente, os quais podem ser dados de forma direta e indireta (ALSHUWAIKHAT e ABUBAKAR, 20o8). A inserção da EA nas escolas é essencial para demonstrar aos estudantes a importância das pequenas atitudes no contexto da preservação ambiental (VERDELONE, CAMPBELL e ALEXANDRINO, 2019). Além do mais, o desenvolvimento da EA voltada aos estudantes poderá sensibilizar toda a comunidade na mudança de seus hábitos incorretos no que tange à preservação (KARATZOGLOU, 2013).

Com relação à ponderação do grau de relevância das atividades do circuito como práticas educativas, as ações com maior representatividade foram: pegada ecológica (7), monstro do lixo (6), abrigo, água e alimento (1) e conhecendo as espécies: macho e fêmea (4), conforme a Figura 4.

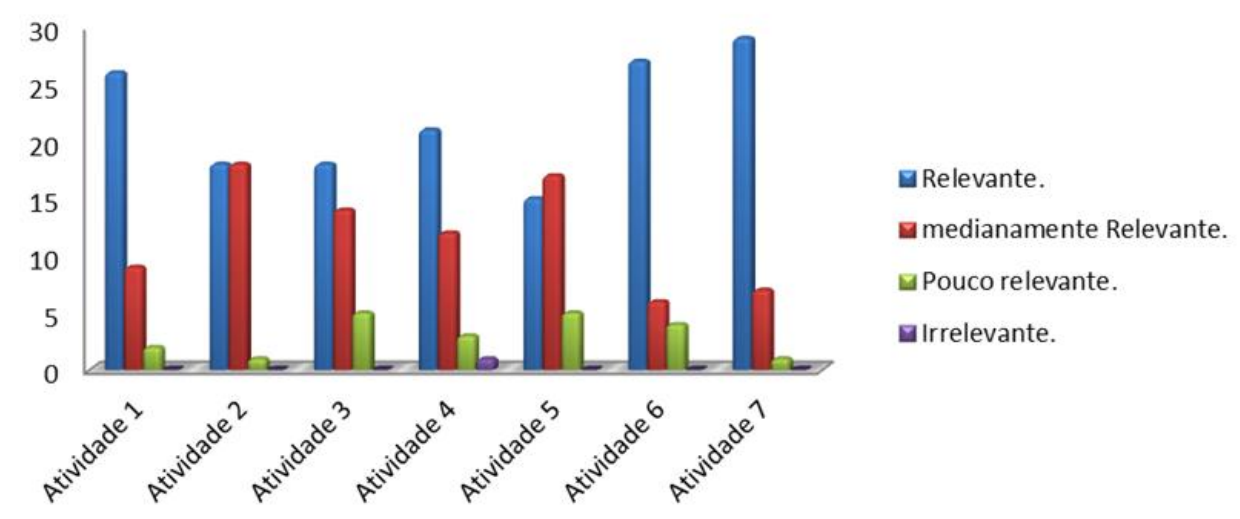

Figura 4: Grau de importância das atividades como prática educativa. Fonte: Elaborado pelas autoras. 
A atividade melhor avaliada, pegada ecológica, refere-se ao impacto coletivo das atividades humanas sobre o meio ambiente. Em síntese, é o efeito no ambiente resultante da produção de bens e serviços, os quais possuem a finalidade de proporcionar um estilo de vida pretendido (RASHID et al, 2018).

Para Danish et al (2019), a pegada ecológica é um indicador de degradação ambiental que tem recebido muita atenção na literatura. Gonzalez e Andrade (2015), ao aplicarem uma metodologia para avaliar o grau de sustentabilidade do consumo da população do estado de Minas Gerais verificaram que o nível de consumo per capita da população do estado gera intensa pressão sobre os recursos da biosfera. No mesmo sentido, Becker et al. (2012) relatam a importância do cálculo da pegada, uma vez que consiste em uma ferramenta para a gestão pública, além de mobilizar a população sobre seus hábitos de consumo e estimular o desenvolvimento de produtos mais sustentáveis, reduzindo o uso de recursos naturais e a emissão de resíduos.

A segunda atividade melhor avaliada, monstro do lixo, consiste em uma oficina pedagógica de EA que propiciou aos estudantes uma vivência prática sobre os problemas inerentes ao descarte incorreto dos resíduos. Para Rhoden, Ribeiro e Samolini (2018), ações de EA que envolvam a gestão dos resíduos sólidos e a participação ativa dos estudantes promovem a conscientização de maneira mais incisiva.

Uma pesquisa realizada por Olivia, Silva e Nascimento Júnior (2014) permitiu concluir que a realização de uma oficina de reutilização de resíduos com futuros docentes possui grande relevância no contexto da EA. Ao término da prática, os autores verificaram que a mesma foi produtiva e motivadora, permitindo aos estudantes uma visão crítica sobre EA. Na mesma direção, Siqueira e Arrial (2018), buscaram dialogar sobre o meio ambiente, redução e disposição final dos resíduos sólidos por meio de uma oficina com alunos do $1^{\circ}$ ano do ensino fundamental, obtendo resultados positivos ao finalizar a atividade.

Esse diálogo sobre resíduos sólidos é primordial, uma vez que a temática pertinente aos impactos ambientais por eles ocasionados exige um esforço que vai além da participação do poder público (RHODEN, RIBEIRO e SALOMINI, 2018).

A Atividade 4, conhecendo as espécies: macho e fêmea, avaliada pelos futuros docentes como "relevante", teve como propósito transmitir o conteúdo e promover a socialização, o que certamente contribuiu para sua avaliação positiva. Segundo Saraiva e Ferreira (2019), a fauna brasileira deve ser explorada no ensino, posto que, atualmente, é um tema que apresenta elevada importância. Além do mais, os autores destacam a necessidade de ampliar as atividades e ações que conduzam a sensibilização sobre este tema no ambiente escolar, como por exemplo, a utilização de diversos tipos de linguagens (escrita, visual, oral ou gestual).

Quanto à avaliação da Atividade 5, jogo de palavras, como "medianamente relevante", provavelmente se deve à dificuldade que os alunos encontraram na formação de sentenças longas de acordo com as normas da Língua Portuguesa, bem como o correto significado ambiental. Observouse, na aplicação desta atividade, maior demora e ansiedade dos participantes se comparada às outras atividades aplicadas. Todavia, apesar da resistência quanto ao tipo de atividade que envolve outro componente curricular, há grande valia em seu emprego, seja para verificar a coerência ambiental dos envolvidos, seja para estimular o raciocínio gramatical por meio da ludicidade.

Os acadêmicos também foram interrogados sobre a utilização das atividades lúdicas em suas futuras práticas docentes, conforme apresentado na Figura 5. 


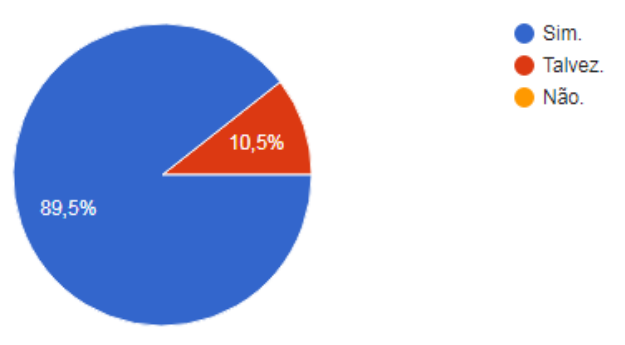

Figura 5: Aceitação da utilização de atividades lúdicas como futuro docente e educador ambiental. Fonte: Elaborado pelas autoras.

De acordo com a Figura 5, os questionados entenderam, em sua maioria (89,5\%), que as atividades lúdicas devem ser desenvolvidas como ferramenta de EA na formação do discente. O resultado obtido na análise da utilização das atividades lúdicas desenvolvidas como forma de crescimento do estudante de licenciatura como futuro profissional da área foi relevante para demonstrar que a ludicidade é um importante fator na construção do conhecimento. Vale ressaltar que nesse questionamento não houve resposta negativa.

Para Rodrigues (2010), há reconhecimento da importância das atividades lúdicas no processo de aprendizagem por docentes, no entanto, muitos não a utilizam. Na mesma direção, Fritz (2013) já afirmava que os profissionais da área de educação deviam utilizar atividades lúdicas na busca por melhores resultados. Este fato também foi evidenciado por Silva et al. (2019) quando citam que muitos professores experientes reconhecem a importância de tais jogos, porém, ainda destinam um tempo mínimo do planejamento de suas atividades para esse fim.

Os futuros docentes e educadores ambientais também foram questionados quanto à importância da forma lúdica de ensino, no ambiente escolar. O resultado de $94,7 \%$ de positividade nas respostas (Figura 6) e ausência de respostas negativas comprova o sucesso da dinâmica e o impacto enriquecedor do lúdico como forma de ensinar e aprender com prazer.

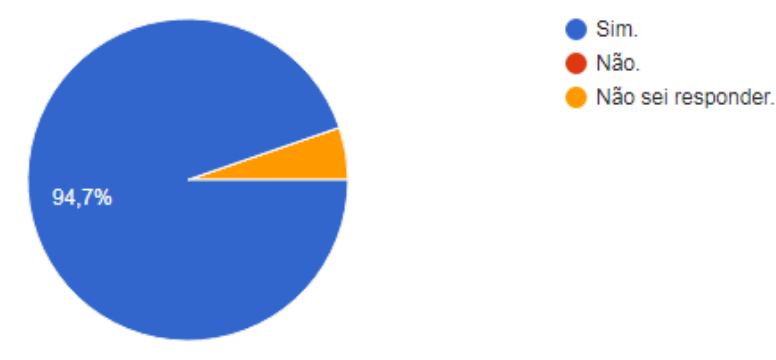

Figura 6: Importância da forma lúdica de ensinar como prática para promover o desenvolvimento global dos discentes em âmbito escolar. Fonte: Elaborado pelas autoras.

No mesmo norte, com relação à forma lúdica de ensinar como prática importante para promover o desenvolvimento global dos discentes em âmbito escolar, os estudantes que participaram desta pesquisa reconheceram a importância das atividades lúdicas, com ações e envolvimentos, para o aprendizado global.

Um estudo realizado por Fritz (2013), no estado do Paraná, identificou que os docentes de escolas municipais reconhecem a importância da ludicidade no processo de ensino aprendizagem e a facilidade em seu desenvolvimento (sala de aula, pátio, entre outros ambientes). Para Baía e Nakayama (2016), o uso do lúdico na condução das atividades de EA promove a construção do processo de ensino 
e aprendizagem por meio de uma linguagem universal: a brincadeira, a qual pode ser utilizada com crianças, jovens e adultos.

Logo, as atividades lúdicas trazem benefícios em todas as fases de desenvolvimento e aprendizagem, não só do aluno, mas também do professor (CONDESSA, PEREIRA e PEREIRA, 2019). O espaço escolar caracteriza-se como um local de convivência e interações sociais, favorável para diversas estratégias de ensino, incluindo os jogos (MOURA et al., 2007).

Por fim, ao serem questionados sobre a participação de atividades em circuitos em outra ocasião apenas 13,2\% disseram já ter participado (Figura 7).

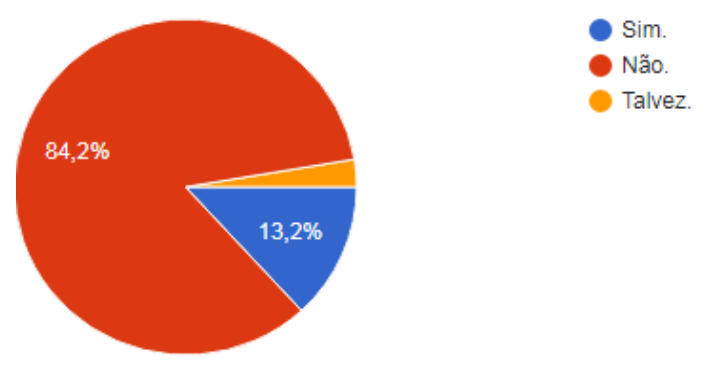

Figura 7: Participação de atividades em circuito em outra ocasião. Fonte: Elaborado pelas autoras.

O resultado demonstrado na Figura 7 retrata o pouco uso de circuitos de atividades como forma de socialização e cognição prazerosa para assimilação do conhecimento. Tendo em vista que o educando não é apenas receptor, mister que seja ativado constantemente. Para Fortuna (200o), o estímulo por meio de atividade lúdica aguça o pensar, sendo a criatividade a principal herança para a vida adulta.

Outrossim, o uso de distintas metodologias estimula a maior participação dos alunos, acarretando em benefícios tanto para o mesmo, quanto para o professor. A dinâmica do processo de ensino e aprendizagem, com a motivação dos discentes/docentes, são os instrumentos necessários para de alcançar uma educação de qualidade, envolvendo o pensar crítico, assimilação do conteúdo e aplicação do conhecimento (KRASILCHIK, 2016).

Vale ressaltar que ao longo das oficinas em circuito, houve reflexão sobre a importância da preservação ambiental para a fauna, discussão do reflexo da degradação dos rios e vegetação na zona rural e urbana, como consequência a dissipação e extinção dos animais. Além disso, houve sensibilização a respeito do desequilíbrio ambiental, que destrói a teia das relações entre os seres vivos.

Para Silva (2018), conduzir ações e posturas ambientalmente adequadas diante dos impactos ambientais propicia aos estudantes um maior grau de sensibilização. A identificação de situações nocivas ao meio ambiente como desmatamento, extinção de animais, poluição, dentre outros assuntos, influencia no aprendizado do aluno e seu crescimento, ocasionando mudanças de hábitos por meio de maiores reflexões.

Assim, percebeu-se nesse estudo que os educadores possuem papel fundamental no processo de sensibilização e incentivo de melhores hábitos no que se refere à preservação ambiental. Suas ações em sala de aula proporcionam aos estudantes uma reflexão e melhor entendimento dos problemas que prejudicam a comunidade em que vivem, contribuindo para a formação de indivíduos com maior comprometimento com o futuro. 
Dessa forma, a inserção de diferentes práticas de ensino, como o lúdico e as atividades em circuito, são essenciais para atingir os resultados almejados na busca pela educação de qualidade e sensibilização dos discentes, sejam crianças, jovens ou adultos.

\section{CONSIDERAÇÕES FINAIS}

A utilização de circuito de atividades lúdicas foi considerada uma importante ferramenta no processo de EA. Apesar dos acadêmicos participantes da proposta terem pouco conhecimento sobre essa metodologia, mostraram-se abertos a novas experiências. Além disso, demonstraram interesse em diversificar suas estratégias de ensino, garantindo mais êxito em sua futura práxis docente.

\section{REFERÊNCIAS}

RASHID, A. et al. Ecological footprint of Rawalpindi; Pakistan's first footprint analysis from urbanization perspective. Journal of Cleaner Production, v.170, p. 362-368, 2018.

ALSHUWAIKHAT, H.M.; ABUBAKAR, I. Na integrated approach to achieving campus sustainability: assessment of the current campus environmental management practices. Journal of Cleaner Production, v. 16, n.16, p. $1711-1822,2008$.

BAÎA, M. C. F.; NAKAYAMA, L. A educação ambiental por meio da ludicidade: uma experiência em escolas do entorno do parque estadual do Utinga. Revista Margens Interdisciplinar, v.7, n.9, p. 89-112, 2013.

BECKER, M.; SILVA, T. A Pegada Ecológica de Campo Grande e a Família de Pegadas. Brasília: WWF Brasil, 2012.

BIANCHESSI, C.; MENDES, A. A. P. Ensino de história por meio de jogos digitais: Relato de aprendizagem significativa com games. Revista Tempos e Espaços em Educação, v.12, n.29, p.145-160, 2019.

BRASIL. Lei no 9.795, de 27 de abril de 1999: Dispõe sobre a educação ambiental, institui a Política Nacional de Educação Ambiental e dá outras providências. Diário Oficial [da] República Federativa do Brasil, v. 79, 1999.

CAMPOS, A. C. M. et al. Avaliação da influência de atividades de educação ambiental na melhoria da coleta seletiva em uma instituição de ensino. Revista Brasileira de Educação Ambiental, v. 14, n.1, p. 456-477, 2019.

CARVALHO, I. C. M. Educação ambiental: a formação do sujeito ecológico. São Paulo, SP: Cortez, p. 256, 2017.

CONDESSA, I.; PEREIRA, V.; PEREIRA, B. A importância da atividade lúdica na escola. Da perspectiva dos professores à realidade vivida. In: Trevisol, M. T. C., Feldkercher, N., Pensin, D. P. Diálogos sobre formação docente e práticas de ensino. Campinas: Mercado de Letras, p. 225-248, 2019.

DANISH et al. Linking economic growth and ecological footprint through human capital and biocapacity. Sustainable Cities and Society, v. 47, p. 1-10, 2019.

DISTERHEFT, A. et al. Sustainable universities - a study of critical success factors for participatory approaches. Journal of Cleaner Production, London, v. 106, n. 53, p. 11-21. 2015.

EVANGELISTA, L. M.; SOARES, M. H. F. B. Atividades lúdicas no desenvolvimento da educação ambiental. Universidade Federal de Goiás. In: II Simpósio de Educação Ambiental e Transdisciplinaridade (SEAT), 2011, Goiânia, GO. Anais... Goiânia, GO: UFG, 2011.

FARIA, L. H. P.; DIETRICH, A. M.; GOMES, V. M. S. O projeto batuclagem e a educação ambiental por meio do brincar: abordando o lúdico no ensino de ciências. Labore em Ensino de Ciências, v.1, n. especial, p. 61-76, 2016.

FORTUNA, T. R. Sala de aula é ligar de brincar? In: XAVIER, M. L. M. e DALLA ZEN, M. I. H. (org.) Planejamento em destaque: análises menos convencionais. Porto Alegre: Mediação, p. 147-164, 2000. (Cadernos de Educação Básica). 
FRITZ, A. N. D. Atividades Lúdicas no Processo de Ensino-Aprendizagem: Um Olhar. 2013. 46f. Monografia (Pós Graduação em Educação) - Universidade Tecnológica do Paraná, Campus Medianeira, Medianeira, 2013.

GONZALEZ, M. H.; ANDRADE, D. C. A sustentabilidade ecológica do consume em Minas Gerais: uma aplicação do método da pegada ecológica. Nova Economia, v.15, n.2, p. 421-446, 2015.

KARATZOGLOU, B. Na in-depth literature review of the evolving roles and contributions of universities to education for sustainable development. Journal of Cleaner Production, v. 49, p. 44-53, 2013.

KAWAMOTO, E. M.; CAMPOS, L. M. Histórias em quadrinhos como recurso didático para o ensino do corpo humano em anos iniciais do ensino fundamental. Ciência \& Educação, v. 20, n. 1, p. 147-158, 2014.

KRASILCHIK, M. Prática de Ensino de Biologia. 4ª̉ed. São Paulo, SP: EDUSP, p. 20o, 2016.

LAYRARGUES, P. P. Determinismo biológico: el desafio de la alfabetización ecológica en la concepción de Fritjof Capra. In: Tópicos en Educación Ambiental, v.4, n.11, p. 7-18. 2002.

LAYRARGUES, P. P.; LIMA, G. F. C. As macrotendências político-pedagógicas da educação ambiental brasileira. Ambiente \& Sociedade, v. 17, n. 1, p. 23-40, 2014.

MOURA, J. B. V. S. et al. Perspectiva da epistemologia histórica e a escola promotora da saúde. História, Ciências, Saúde-Manguinhos, v.14, n.2, p. 489-501, 2007.

OLIVEIRA, C. S. et al. Oficina de educação, memória, esquecimento e jogos lúdicos para a terceira idade. Revista Ciência em Extensão, v.8, n.1, p.8-17, 2012.

OLIVEIRA, L. A.; SILVA, A. N.; NASCIMENTO JUNIOR, A. F. Oficina de reutilização de materiais: Educação ambiental crítica na formação de professores. Fórum Ambiental da Alta Paulista, v.10, n.6, 2014.

OLIVEIRA, N. M. et al. Imagens de Educação Ambiental de futuros professores de Ciências Biológicas. Revista Práxis Online, v. 09, n.9, p. 56-63, 2013.

REIGOTA, M. O que é educação ambiental. Tatuapé, SP: Brasiliense, p. 71, 2017.

REVERBEL, O. Um caminho do teatro na escola. 2. Ed. São Paulo, SP: Scipone, p. 174, 1997.

RHODEN, V.; RIBEIRO, L. B.; SALOMONI, S. E. Relatos de atividades de conscientização e educação ambiental sobre o destino correto dos resíduos sólidos em São Borja - RS. Revista Eletrônica de Extensão, v. 15, n.28, p. 77-86, 2018.

RODRIGUES, G. F. A visão dos professores de Ciências e Biologia sobre o brincar e o silêncio em sala de aula. Trabalho de Conclusão de Curso (Licenciatura em Ciências Biológicas) - Universidade Federal do Rio Grande do Sul, Porto Alegre - RS, 2010.

SACCHETTO, K. K. O Ambiente Lúdico como Fator Motivacional na Aprendizagem Escolar. Cadernos de PósGraduação em Distúrbios do Desenvolvimento, v.11, n.1, p. 28-36, 2011.

SARAIVA, V. R.; FERREIRA, A.V-B. O zoológico como um espaço de ciência para a sensibilização de estudantes sobre a temática biodiversidade brasileira. Revista Eletrônica do Mestrado em Educação Ambiental, v. 36, n.1, p. 2014-220, 2019.

SILVA, A. M. T. B.; METTRAU, M. B.; BARRETO, M. S. L. O lúdico no processo de ensino-aprendizagem das ciências. Revista Brasileira de Estudos Pedagógicos, v. 88, n. 220, p.445-458, 2007.

SILVA, F. S. et al. As contribuições dos jogos e brincadeiras no processo de ensino-aprendizagem. Brazilian Journal of Development, v.5, n.4, p. 3820-3833, 2019.

SILVA, L. O. A importância da educação ambiental. Revista Científica Multidisciplinar Núcleo do Conhecimento, v.5, n. 10, p. 91-101, 2018. 
SIQUEIRA, V. S.; ARRIAL, L. R. Educação ambiental através da reutilização de resíduos sólidos para a elaboração de brinquedos. Revista Thema, v. 15, n.3, p. 927-942, 2018.

VERDELONE, T. H.; CAMPBELL, G.; ALEXANDRINO, C. R. Trabalhando educação ambiental com turmas do ensino fundamental I. Brazilian Journal of Development, v.5, n.6, p. 4675-4687, 2019.

Norma Barbado: Graduação em Ciências Exatas pela Associação Paranaense de Ensino e Cultura (1989), licenciatura em Biologia pela Universidade do Oeste Paulista (1998), mestrado em Educação pela Universidade do Oeste Paulista (2008) e doutorado em Agronomia pela Universidade Estadual do Oeste do Paraná (2014). Atuou como Orientadora Educacional e supervisora no curso FIC Condutor Ambiental pelo programa Pronatec em 2013 e 2014 no IFPR Campus Foz do Iguaçu, onde também lecionava Biologia para o Ensino Médio Integrado. Atualmente é docente do curso de Mestrado em Sustentabilidade IFPR/UEM, professora e Coordenadora da Licenciatura em Ciências Biológicas do IFPR Campus Umuarama.

E-mail:norma.barbado@ifpr.edu.br

Juliana Conter Pereira Kobren: Mestranda no Programa de Pós-Graduação em Sustentabilidade (UEM/IFPR). Pós-Graduada pelo Centro Universitário Curitiba (UNICURITIBA), com Título de Especialista em Direito Tributário (2007). Graduada em Direito pela Universidade Estadual do Norte do Paraná (UENP) na Faculdade Estadual de Direito do Norte Pioneiro (2003). Graduada em Desenho Industrial com ênfase em Projeto de Produto pela Pontifícia Universidade Católica do Estado do Paraná (1997).

E-mail: juconter@gmail.com

Luciana Nunes dos Santos: Graduada em Engenharia Ambiental pela Universidade Estadual de Maringá (UEM. Participou do Projeto de Ensino sobre gerenciamento de Resíduos da UEM - campus Umuarama (2012-2013) e do projeto de iniciação científica sobre gerenciamento de resíduos perfurocortantes gerados por diabéticos insulino-dependentes do município de Umuarama (2013-2015). Bolsista PIBICCNPQ/Fundação Araucária (2013-2015). Atualmente, discente no Programa de Pós-Graduação em Sustentabilidade, pela UEM.

E-mail: eng.ambiental.lununes@gmail.com

Paula Andréia Gomes da Cruz: Graduação em Arquitetura e Urbanismo pela Universidade Paranaense (2006). Especialização em Arquitetura pela Universidade Estadual de Londrina (2008). Atualmente é professora da Universidade Paranaense. Tem experiência na área da Arquitetura e Urbanismo, com ênfase em Projeto Arquitetônico, atuando principalmente nos seguintes temas: representação, história, teoria, ensino e prática projetual do Projeto Arquitetônico.

E-mail: arquitetapaulagomes@gmail.com 